Article

\title{
Biochemical Pathways and Enhanced Degradation of Dioctyl Phthalate (DEHP) by Sodium Alginate Immobilization in MBR System
}

\author{
Ke Zhang ${ }^{1,}$, Xiangling $\mathrm{Wu}^{1}$, Hongbing Luo ${ }^{1}$, Wei Wang ${ }^{2}$, Siqiao Yang ${ }^{1}$, Jian Chen ${ }^{1}$, \\ Wei Chen ${ }^{1}$, Jia Chen ${ }^{1}$, You Mo ${ }^{1}$, Lin Li ${ }^{1}$ \\ ${ }^{1}$ College of Civil Engineering, Sichuan Agricultural University, Dujiangyan 611830, PR China; \\ 2 School of Environment, Harbin Institute of Technology, Harbin 150090, Heilongjiang, PR China. \\ * Correspondence: zhangke@sicau.edu.cn; Fax: 028-87133366
}

\begin{abstract}
A bacterial strain that could effectively degrade DEHP was isolated from the activated sludge and identified as Bacillus sp. by DNA sequencing. The biochemical degradation pathway of DEHP was further analyzed by GC-MS, and the results showed that DEHP was first decomposed into phthalates (DBP). Diuretic sylycol (DEP) was then generated, and phthalates (PA) were generated by a continuous de-ehelateization reaction. Phthalic acid (PA) was oxidized, dehydrogenated, and decarboxylated into protocatechins. Protocatechins enter the TCA cycle through orthotopic ring opening. To enhance DEHP degradation, sodium alginate and calcium chloride were used as embedding and cross-linking materials, and the strain was immobilized. The immobilization conditions were optimized via an orthogonal experiment, and the results showed that the optimal immobilization conditions were SA mass fraction of $4 \%, \mathrm{CaCl} 2$ mass fraction of $5 \%$, ratio of bacteria to SA of 1:1, and the crosslinking time of 6 hours. The immobilized bacteria agent was further applied to MBR systems. The results showed that the removal rate of DEHP $(5 \mathrm{mg} / \mathrm{L})$ in the system by immobilized bacteria was $91.9 \%$, which is significantly higher than that of free bacteria. The 3, 4-dioxygenase gene and microbial community dynamics were analyzed by q-PCR and Illumina Miseq sequencing. The q-PCR results showed that the number of copies of 3, 4dioxygenase gene in the immobilized system was significantly higher than that of free bacteria. Illumina Miseq sequencing results showed that Micromonospora, Rhodococcus, Bacteroides and Pseudomonas were the dominant generas in the MBR system. The analysis of bacterial community structure indicated that immobilization technology had a positive impact on the system stability. The results implied that this immobilized technique had potential applications in DEHP wastewater treatment.
\end{abstract}

Keywords: DEHP; biochemical pathways; immobilization; MBR; bacterial community dynamics

\section{Introduction}

Phthalate (PAEs) are a series of endocrine disruptors [1], widely used as plasticizers in industry [2]. Its annual production and consumption exceed 2.5 million $t$, accounting for $80 \%$ of the total production of plasticizers [3]. The binding of PAEs to plastic molecules is mainly through hydrogen bonds and van der Waal. There is no direct connection of chemical bond: it is easy to enter the environment during the production, storage, use and processing of industrial products [4, 5]. Many studies have shown that industrial and agricultural areas in China are suffering from PAEs pollution to varying degrees [6, 7]. PAEs of waste plastic recycling stations in salt beach range from $200-1200$ $\mathrm{ng} \cdot \mathrm{m}^{-3}[8]$. The concentrations of DEHP, DMP, DBP and DOP in the water samples of Anshan city were $18.1863 \mathrm{mg} / \mathrm{L}$ (DOP) - $0.0446 \mathrm{mg} / \mathrm{L}$ (DBP) [9]. PAEs in the soil of many greenhouse vegetable bases in China exceed the standard [10,11]. DEHP is toxic to wheat root tissue [12]. DnBP in soil can change the abundance, structure and composition of bacteria in rhizosphere of cucumber seedlings, and ultimately lead to the decrease of protein content in roots [13]. PAEs are not easy to volatilize and insoluble in water, and they can be stable in the soil, which has serious harm to soil 
microorganisms, plants and human health. As the most widely used PAEs, Di-(2-ethylhexyl) phthalate (DEHP) has been detected around the world in recent years [14]. Many studies have proved that DEHP has strong toxicity, including carcinogenicity, teratogenicity, reproductive toxicity, hepatotoxicity, mutagenicity and endocrine disruption toxicity [15, 16]. In Japan, DEHP has caused 13.7 million disability-adjusted life years (DALYs) to humans [17]. DEHP also exist extensively in sewage treatment plants [18]. Therefore, it is necessary and urgent to conduct DEHP remediation research.

Biodegradation has been widely used because of its fast growth cycle, high removal rate and low cost [19]. Abiotic degradation is rarely used to remove DEHP. Due to the extremely slow photodegradation of DEHP under natural conditions, the hydrolysis rate of DEHP under neutral acid and alkalineconditions is almost negligible, with a half-life of about 2000 years [20, 21]. At present, many DEHP-degrading bacteria have been isolated from different environments, such as Mycobacterium, Nocardia, Pseudomonas, Bacillus, etc. [22, 23]. Previous studies on the degradation pathways of DEHP have shown that DEHP may be converted to MEHP through esterase hydrolysis, then further hydrolyzed to PA, and finally gradually mineralized [24-26]. It has also been reported that the DEHP degradation pathway is that DEHP first shortens the side chains by $\beta$-oxidation to form medium-chain DBP, then hydrolyzes into short-chain DEP and finally converts into PA [27]. In short, the degradation pathways of DEHP are not clear yet. Moreover, the existing research on DEHP degradation mainly focused on anaerobic conditions, with the disadvantages of incomplete degradation and long cycle. Compared with anaerobic degradation, aerobic degradation has the advantages of complete and rapid degration. This study was mainly carried out under aerobic conditions and the biochemical degradation pathways were investigated. Microbial immobilization technology is to confine free cells to specific space areas by chemical or physical methods in order to maintain cell viability [28]. In recent years, it mainly appears in the research of sewage denitrification and ammonia removal. The commonly used embedding methods include interception, adsorption, encapsulation and synthesis of polymers. DONG et al. [29] found that when the molar ratio of COD to $\mathrm{NO}_{3}-\mathrm{N}$ was 2.0 , the filling rate of carrier volume was $20 \%$, and the hydraulic retention time was $38 \mathrm{~h}$, the TN removal rate of wastewater in the reactor was 98\%. ZHANG et al. [30] used corncob-SA to immobilize DOP-degrading bacteria to degrade DOP in soil. The removal rate was 60 and 2.3 times higher than that of corn cob or free bacteria, respectively. In general, past studies have shown that immobilization technology can effectively improve the efficiency of cell degradation of organic compounds [31]. However, there are few reports on the immobilization of DEHP-degrading bacteria. As a refractory organics, DEHP has a low degradation rate. Immobilization technology may promote DEHP. However, the effects of immobilized technique on DEHP degradation and the associated microbial mechanism are still not clear.

In this study, aerobic degradation pathways of DEHP and orthogonal experiment of immobilization conditions were conducted, and the feasibility of its application in bioreactor and associated microbial processes were further discussed. The results from this study are expected to provide valuable information for DEHP wastewater treatment.

\section{Materials and Methods}

\subsection{Chemicals and medium}

The purity of DEHP used in this experiment is 99\% (Aldrich-Sigma Company in St. Louis, USA). The solvents (methanol, ethyl acetate) are of high performance liquid chromatography (HPLC), and the other chemical reagents are analytical pure. Minimal Salt Medium [MSM]: $\mathrm{MgSO}_{4} \cdot 7 \mathrm{H}_{2} \mathrm{O} 0.4 \mathrm{~g}$, $\mathrm{CaCl}_{2} \cdot 2 \mathrm{H}_{2} \mathrm{O} 0.05 \mathrm{~g}, \mathrm{~K}_{2} \mathrm{HPO}_{4} 1.5 \mathrm{~g}, \mathrm{KH}_{2} \mathrm{PO}_{4} 1.52 \mathrm{~g}, \mathrm{FeSO}_{4} \cdot \mathrm{H}_{2} \mathrm{O} 0.04 \mathrm{~g}, \mathrm{NaNO}_{3} 0.5 \mathrm{~g},\left(\mathrm{NH}_{4}\right)_{2} \mathrm{SO}_{4} 1.00$ g, $\mathrm{FeCl}_{3}$ $0.14 \mathrm{~g}, \mathrm{H}_{2} \mathrm{O} 1000 \mathrm{~mL}$. LB liquid medium: yeast extract $5 \mathrm{~g}$, peptone $10 \mathrm{~g}, \mathrm{NaCl} 5 \mathrm{~g}, \mathrm{H}_{2} \mathrm{O} 1000 \mathrm{~mL}, \mathrm{pH} 7$. The solid medium was prepared by adding $20 \mathrm{~g}$ agar into the above two liquid media, and the DEHP concentration was added into MSM according to actual needs.

2.2 Identification of degrading bacteria 
Activated sludge samples were collected from the secondary sedimentation tank of Xinjin Municipal Sewage Treatment Plant in Sichuan Province (30 $24^{\prime} 49^{\prime \prime}$ N $103^{\circ} 49^{\prime} 11^{\prime \prime}$ E). Sludge samples were concentrated according to literature [32]. The $\mathrm{pH}$ value of culture medium was adjusted to 7.0 by $\mathrm{HCl}$ and $\mathrm{NaOH}$. After enrichment, the concentration of DEHP was gradually increased to $5 \mathrm{mg} / \mathrm{L}$ by gradient pressure domestication. The bacteria were further purified by plate method. Finally, the isolate was re-inoculated into MSM agar plate containing $5 \mathrm{mg} / \mathrm{L}$ DEHP to confirm its degradation ability. The strain SAS-7 with the best degradation effect of DEHP was selected and stored in a slant medium at 4 ${ }^{\circ} \mathrm{C}$.

The bacterial genomic DNA was extracted by the extraction kit (TianGen Biotechnology Co., Ltd., Beijing) according to the instructions. The bacterial primers used in this study were 27F (5'AGAGTTTGATCCTGGCTCAG-3') and 1429R (5'-GGCTACCTTGTTACGACTT-3'). PCR (Bio-Rad, USA) was carried out under the following conditions: preheating at $95^{\circ} \mathrm{C}$ for $2 \mathrm{~min}$, denaturing at $94^{\circ} \mathrm{C}$ for $1 \mathrm{~min}$, annealing at $56^{\circ} \mathrm{C}$ for $1 \mathrm{~min}$, expanding at $72^{\circ} \mathrm{C}$ for $3 \mathrm{~min}$, cycling 30 times and expanding at $72^{\circ} \mathrm{C}$ for $8 \mathrm{~min}$. The PCR product was purified from the universal DNA Gel Extraction Kit (Tiangen bio Polytron Technologies Inc, Beijing), cloned into the pGM-T vector of Escherichia coli, and plasmids were extracted from positive clones by plasmid Mini Kit, and DNA sequencing was performed by Sangon company (Shanghai). Then, BLAST X homology search was performed on the obtained sequences, and phylogenetic tree was constructed by using neighborhood connection method in MEGA5 (version 6.0, USA) software package.

\subsection{Analysis of metabolites and degradation pathways}

DEHP concentration was determined by high performance liquid chromatography (Aglient 1200) with ultraviolet detector and Water Sunfire C18 column $(20 \mathrm{~mm} \times 4.6 \mathrm{~mm} \times 5 \mu \mathrm{m})$. The chromatographic conditions were as follows: the volume ratio of mobile ethanol to water $(90: 10)$ and the flow rate $(1$ $\mathrm{mL} / \mathrm{min}$ ). The extraction and purification methods were as follows: adding ethyl acetate to each sample, shaking and mixing for 5 minutes, separating water and organic phase at a speed of $8000 \mathrm{rpm}$, and rotating for 5 minutes. The aqueous phase was extracted twice under the same volume of ethyl acetate, which was dried and evaporated on anhydrous sodium sulfate and then dissolved in $10 \mathrm{~mL}$ methanol. Then $1 \mathrm{~mL}$ methanol mixed with DEHP was taken through a filter membrane with a pore diameter of $0.22 \mu \mathrm{m}$, and finally $20 \mu \mathrm{L}$ filtrate was injected into the HPLC system.

DEHP degradation intermediates were detected by gas chromatography-mass spectrometry (GCMS), and the obtained data were compared with the mass spectrometry library in the MS system to determine the types of metabolites. The detection work was completed by Sichuan Keyuan Engineering Technology co., LTD, China.

\subsection{Immobilization of SAS-7 strain}

Sodium alginate and calcium chloride were used as embedding and crosslinking materials. SAS-7 cell resuspension $\left(\mathrm{OD}_{600}=1.0,5 \mathrm{~mL}\right)$ was mixed with MSM $(20 \mathrm{~mL})$ in a conical flask $(200 \mathrm{~mL})$, and then the conical flask was sterilized. Subsequently, the MSM containing SAS-7 strain was combined with sterile $\mathrm{SA}$, and the mixture was dripped into the gel solution $\left(\mathrm{CaCl}_{2}\right)$ with the help of a syringe at $4^{\circ} \mathrm{C}$. Thus, spherical immobilized bacterial beads with a diameter of $4 \sim 5 \mathrm{~mm}$ were obtained. Blank control beads without SAS-7 cells were prepared by the same method. In order to obtain the optimal immobilization conditions, the mass fraction of sodium alginate, the mass fraction of $\mathrm{CaCl}_{2}$, the volume ratio of bacteria to sodium alginate, and the crosslinking time were taken as factors to design the fourfactor and three-level orthogonal experiment $\mathrm{L}_{9}(3)^{4}$ (Table 1). Immobilized beads were washed three times with sterile distilled water and then stored at $4^{\circ} \mathrm{C}$ for subsequent experiments. 
Table 1. Factors and levels of orthogonal experiment design.

\begin{tabular}{ccccc}
\hline Levels & Factor $\mathbf{A}$ & Factor B & Factor C & Factor D \\
\hline $\begin{array}{c}\text { SA } \\
\text { concentration } \\
(\%)\end{array}$ & $\begin{array}{c}\mathrm{CaCl}_{2} \\
\text { concentration } \\
(\%)\end{array}$ & $\begin{array}{c}\text { Ratio of bacteria to } \\
\text { SA } \\
(\%)\end{array}$ & $\begin{array}{c}\text { Cross-linking } \\
\text { time } \\
(\mathrm{h})\end{array}$ \\
\hline & & & $1: 1$ & 5 \\
2 & 5 & 3 & $1: 2$ & 6 \\
3 & 6 & 5 & $2: 1$ & 7 \\
\hline
\end{tabular}

\subsection{Reactor start-up and operation}

In this study, each MBR reactor was inoculated with $0.6 \mathrm{~L}$ activated sludge. Artificial water distribution was used as reactor feed water, in which $\mathrm{NH}_{4} \mathrm{SO}_{4}$ was the nitrogen source, $\mathrm{KH}_{2} \mathrm{PO}_{4}$ was the phosphorus source, $\mathrm{KCl} 5000 \mathrm{mg} / \mathrm{L}$ was added, trace elements $\mathrm{FeSO}_{4} \cdot 7 \mathrm{H}_{2} \mathrm{O} 5000 \mathrm{mg} / \mathrm{L}, \mathrm{ZnCl}_{2} 1000$ $\mathrm{mg} / \mathrm{L}, \mathrm{MnCl}_{2} 1000 \mathrm{mg} / \mathrm{L}, \mathrm{CoCl}_{2} \cdot 6 \mathrm{H}_{2} \mathrm{O} 200 \mathrm{mg} / \mathrm{L}, \mathrm{CuSO}_{4} \cdot 5 \mathrm{H}_{2} \mathrm{O} 100 \mathrm{mg} / \mathrm{L}$ were added, and the $\mathrm{pH}$ was adjusted to 7.0. According to the relevant experiments on the amount of bacteria incobulated and the relative results of aerobic degradation [33], the inoculation amount of DEHP degradation bacteria in this experiment was $7 \%$ of the volume of sludge inoculation. MBR reactor system was controlled by relay. The process flow diagram is shown in figure 1. Continuous influent was adopted, dissolved oxygen was $4 \sim 5 \mathrm{mg} / \mathrm{L}$, operating temperature was $24^{\circ} \mathrm{C}$, hydraulic retention time was $48 \mathrm{~h}$.

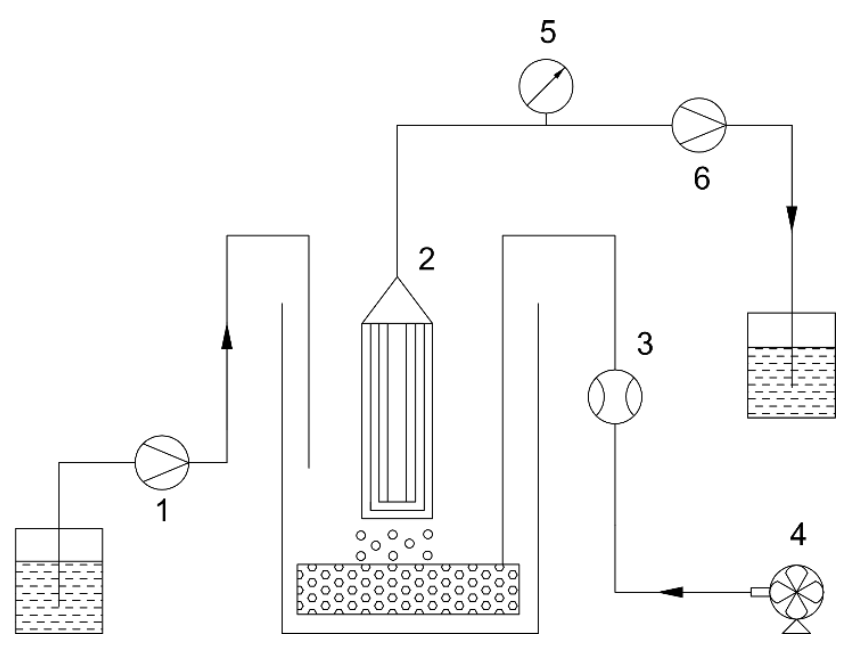

Figure 1. MBR flow chart and reactor.

\subsection{Detection of 3,4-Dioxygenase gene in $M B R$ by $q-P C R$}

The total number of 3,4-Dioxygenase genes of DEHP-degrading bacteria in MBR were detected by q-PCR using ABI 7500 Real-time Polymerase Chain Reactor (Applied Biosystem, USA). The product of 3,4-Dioxygenase 16S rRNA PCR was purified and ligated into pMD18-T vector (TaKaRa, Japan) and transformed into Escherichia coli DH5a (TaKaRa, Japan). Plasmid DNA was extracted by Plasmid Extraction Kit (Transgen, Beijing). DNA concentration and quality were measured by NanoDrop ND-1000 (American Thermal Fisheries Science Corporation). The $20 \mu \mathrm{L}$ reaction mixture contains 10 Ml SYBR Premix Ex Taq II (Ex Taq II enzyme pre-mixed with SYBRR dye for fluorescence quantification) (Takara, Japan). Each primer extracts $0.6 \mu \mathrm{L}, 1 \mu \mathrm{L}$ genomic DNA, and the remainder is filled by double-distilled hydrogen peroxide. The program is set as follows: preheating for 5 minutes at $95^{\circ} \mathrm{C}$, denaturation for 1 minute at $94^{\circ} \mathrm{C}$, annealing for 1 minute at $56^{\circ} \mathrm{C}$, expansion for 3 
minutes and 30 cycles at $72^{\circ} \mathrm{C}$. The plasmid containing $16 \mathrm{~S}$ rRNA gene sequence of bacteria was diluted to a series of concentrations, each concentration differed by 10 times. The standard curve of plasmid was drawn. The $\mathrm{R}^{2}$ of the standard curve was $>0.99$. All standards and samples are in triplicate.

\subsection{Microbial community analysis}

In order to explore the bacterial community structure dynamics after the free and immobilized degradation bacteria SAS-7 were introduced into the MBRs, the sewage samples in the MBR were collected every 10 days for Illumina MiSeq sequencing. Three samples were collected at a time. After the immobilized beads were crushed, total DNA was extracted through Power Soil DNA Isolation Kiit (MOBIO Laboratories Inc., USA). For gene amplification of 16s rDNA V3-V4 area, choose 341F (CCCTACACGACGCTCTTCCGATCTGCCTACGGGNGGCWGCAG) and $80 \quad \mathrm{R}$ (GACTGGAGTTCCTTGGCACCCGAGAATTCCAGACTACHVGGGTATCTAATCC) as a primer. Both forward and reverse primers were tagged with adapter, pad and linker sequences. Each bar code sequence was added to the reverse primers, and multiple samples were collected in one MiSeq sequence [34]. The amplified products were loaded onto $1.2 \%$ agarose gel and purified by E.Z.N.A.TM Gel Extraction Kit (Omega BioTek Inc., Norcross, Georgia) [35]. FTC-3000 real-time PCR method was used to determine DNA concentration and quality.The amplicon was then used for MiSeq sequencing. After sequencing, the data were analyzed by different procedures combined with the quantitative analysis of standard pipes in QIIME Pipeline [36] Eliminate low-quality reads, adapters, barcodes and primers. Using UCLUST algorithm, the remaining $16 \mathrm{~S}$ rRNA sequences were clustered into operational classified nitrogen sources (OTUs) with a distance limit of 0.03 . The Shannon's diversity index of each sample was calculated in MOTHUR by clustering file to estimate the diversity of the community.

\section{Results}

\subsection{Isolation and identification of strains}

A Gram-positive bacterium named SAS-7 was obtained, which can effectively utilize DEHP (5 $\mathrm{mg} / \mathrm{L}$ ) as carbon source and energy source. Strain SAS-7 showed light yellow, wet surface of colony, round shape and neat edge. Electron microscopy showed that cells were rod-shaped with spores.

The 16S rDNA sequence of strain SAS-7 was stored in NCBI with the Accession number MK182383. A phylogenetic tree based on the 16S rRNA gene sequences of strain SAS-7 and its close relatives was constructed (figure 2). According to figure 2, the similarity between SAS-7 and Bacillus aerophilus JCM 13347 (AJ831844) was 100\%. Based on the morphological characteristics of the strain and $16 \mathrm{~S}$ rRNA gene sequence analysis, the strain was identified as Bacillus sp.

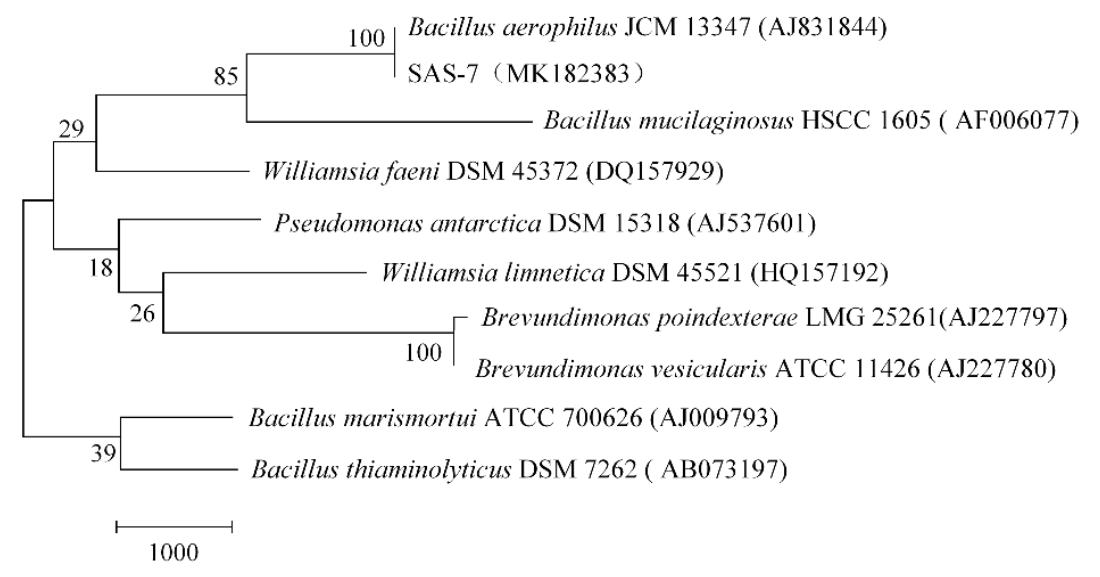

Figure 2. Phylogenetic tree of SAS-7 and its related species based on 16S rRNA gene sequence. 


\subsection{Degradation pathways of DEHP}

To ensure that DEHP will not cause secondary pollution to the environment in the process of bioremediation. In this study, the metabolites of DEHP under the degradation of SAS-7 were detected by GC-MS. These intermediates include 2-ethylhexyl phthalate (DEHP), dibutyl phthalate (DBP), diethyl phthalate (DEP), phthalic acid (PA) and protocatechol, etc.

Based on the results of GC-MS, the degradation pathways of DEHP by SAS-7 were analyzed. The degradation pathways were inferred as shown in figure 3. 2-ethylhexyl phthalate (DEHP) was first decomposed into dibutyl phthalate (DBP), then hydrolyzed to diethyl phthalate (DEP), which was converted into phthalic acid (PA) through continuous deesterification. Phthalic acid (PA) is oxidized, dehydrogenated and decarboxylated to produce protocatechol. Protocatechol enters TCA cycle through ortho-ring opening, and finally completes the mineralization of DEHP.

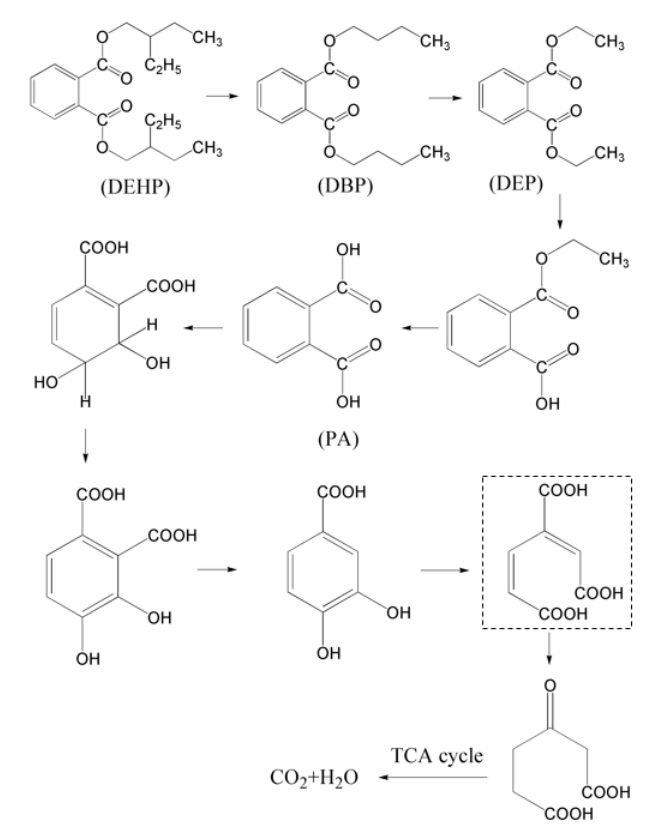

Figure 3. Proposed pathways of DEHP degradation by strain. (Material marked by dotted lines is undetected in GC-MS)

\subsection{Optimization of immobilization conditions}

To optimize the immobilization conditions, L9 $\left(3^{4}\right)$ orthogonal experiment (Table 1) was designed. Sodium alginate mass fraction (A), $\mathrm{CaCl}_{2}$ mass fraction (B), ratio of bacteria to $\mathrm{SA}(\mathrm{C})$ and crosslinking time (D) were taken as factors. According to the $\mathrm{R}$ value showed in table 1 , the order of the influence of each factor on DEHP removal rate is: $\mathrm{B}>\mathrm{D}>\mathrm{A}>\mathrm{C}$. Different $\mathrm{CaCl}_{2}$ mass fraction has the greatest influence on DEHP removal rate, followed by crosslinking time. The ratio of bacteria to SA has the smallest influence on DEHP removal rate. According to the $\mathrm{K}$ value, the optimum immobilization conditions were $\mathrm{A}_{1} \mathrm{~B}_{3} \mathrm{C}_{1} \mathrm{D}_{2}$, that is, $\mathrm{SA}$ mass fraction was $4 \%, \mathrm{CaCl}_{2}$ mass fraction was $5 \%$, bacteria to SA ratio was 1:1, cross-linking time was 6 hours.

Table 2. Orthogonal experimental results of immobilized DEHP degrading bacteria.

\begin{tabular}{cccccc}
\hline Trial No. & \multicolumn{9}{c}{ Factors } & Degradation rate(\%) \\
\cline { 2 - 5 } & A & B & C & D & \\
\hline 1 & 1 & 1 & 1 & 1 & 63.4 \\
2 & 1 & 2 & 2 & 2 & 57.8 \\
3 & 1 & 3 & 3 & 3 & 61.3
\end{tabular}




\begin{tabular}{|c|c|c|c|c|c|}
\hline 4 & & 1 & 2 & 3 & 54.8 \\
\hline 5 & & 2 & 3 & 1 & 49.7 \\
\hline 6 & & 3 & 1 & 2 & 66.3 \\
\hline 7 & & 1 & 3 & 2 & 56.9 \\
\hline 8 & & 2 & 1 & 3 & 50.3 \\
\hline 9 & & 3 & 2 & 1 & 61.5 \\
\hline $\mathrm{k}_{1}^{\mathrm{a}}$ & 60.833 & 58.367 & 60.000 & 58.200 & \\
\hline $\mathrm{k}_{2}$ & 56.933 & 52.600 & 58.033 & 60.333 & \\
\hline $\mathrm{k}_{3}$ & 56.233 & 63.033 & 55.967 & 55.467 & \\
\hline $\mathrm{R}^{\mathrm{b}}$ & 4.600 & 10.433 & 4.033 & 4.866 & \\
\hline
\end{tabular}

$\mathrm{R}^{\mathrm{b}}$ indicates the range of DOP degradation under different factors.

$\mathrm{k}_{1}$, $\mathrm{k}_{2}$ and $\mathrm{k}_{3}$ represent the average degradation rates of DEHP at 1, 2 and 3 levels under different factors, respectively. Factors $\mathrm{A}, \mathrm{B}, \mathrm{C}$ and $\mathrm{D}$ represent $\mathrm{SA}$ concentration, $\mathrm{CaCl}_{2}$ concentration, Ratio of bacteria to $\mathrm{SA}$, cross-linking time, respectively.

\subsection{DEHP removal rate in $M B R$ reactor}

To evaluate the performance of the bioreactor, the effluent samples of MBR reactor were collected daily and the removal rates of COD and DEHP were measured. Three experimental groups $\mathrm{T} 1, \mathrm{~T} 2$ and CK were set up (T1, T2 and CK refer to the experimental group with adding free SAS-7 bacteria, immobilized SAS-7 bacteria and no SAS-7 bacteria, respectively). The wastewater containing $5 \mathrm{mg} / \mathrm{L}$ DEHP were pumped into the three reactors. As shown in Fig. 4, the removal rates of organic pollutants in the first 10 days were not significantly different under different conditions. On the $12^{\text {th }}$ day, the removal rates of DEHP in CK, T1 and T2 were 15\%, 33\% and 40\%, respectively, and the removal rates of COD were between $55 \%$ and $56 \%$. Obviously, the DEHP and COD degradation rate of $\mathrm{T} 2$ system was significantly higher than that of $\mathrm{T} 1$ and $\mathrm{CK}$, indicating that immobilization technology shortened the start-up time of the reactor. On the $28^{\text {th }}$ day, the removal rate of DEHP in sewage treated with immobilized bacteria reached $63 \%$, which was $9 \%$ higher than that of free bacteria. At 37 days, the remaining amount of DEHP between $\mathrm{T} 1$ and $\mathrm{T} 2$ sewage showed the greatest difference. The removal rate of DEHP in $\mathrm{T} 1$ was $84 \%$, the removal rate of $\mathrm{T} 2$ was $73 \%$, and the difference was $11 \%$. From the $28^{\text {th }}$ day to the $37^{\text {th }}$ day, the degradation rate of $\mathrm{T} 2$ system increased faster than that of T1 system, indicating that immobilization technology played a role in significantly improving the degradation rate. At the end of the experiment (day 46), the removal rates of DEHP and COD in $\mathrm{T} 2$ were $91.9 \%$ and $90.7 \%$, respectively, while the removal rates of DEHP and COD in T1 were $84.7 \%$ and $86.7 \%$, respectively. The results showed that the immobilized bacteria not only accelerated the degradation rate but also improved the degradation effect. In general, the removal effect of immobilized bacteria on DEHP and COD in sewage was better than that of free bacteria. 


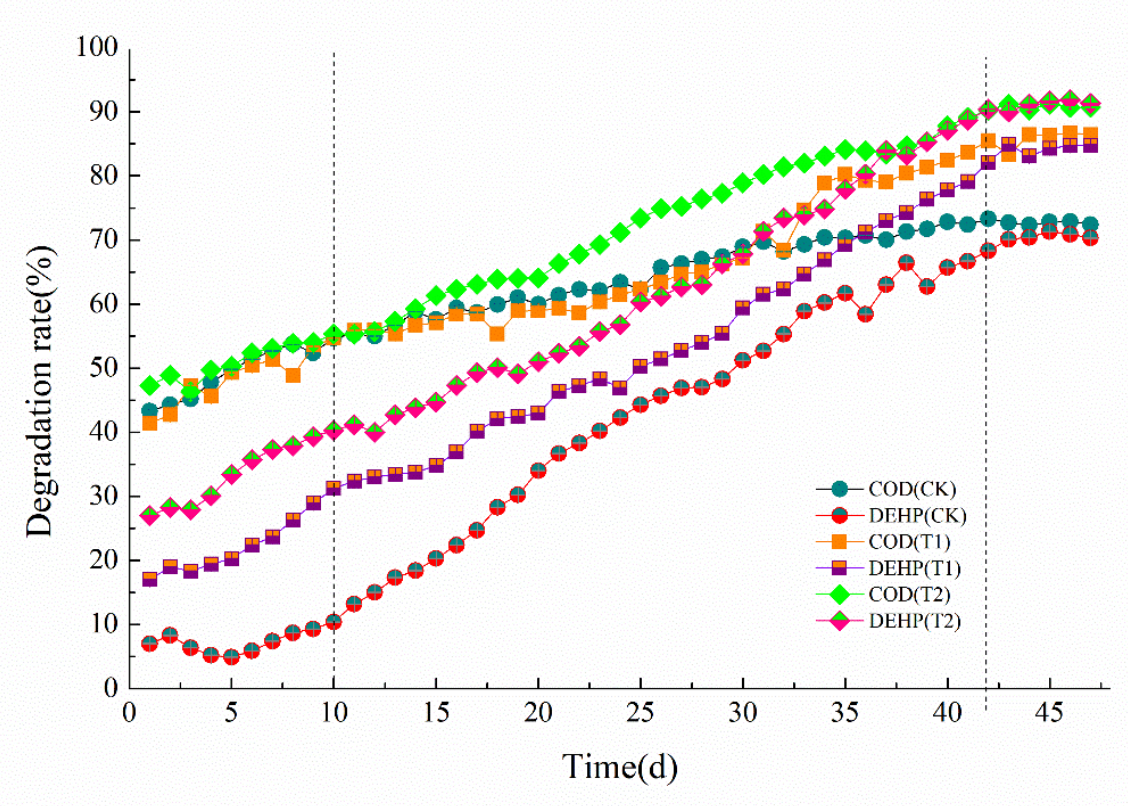

Figure 4. Removal effect of free bacteria (T1) and immobilized bacteria (T2) in MBR reactor on DEHP

\section{5. $q-P C R$ analysis of degrading gene 3,4-dioxygenase}

To investigate the effect of immobilization technology on the quantitative characteristics of DEHP degrading genes in bioreactors, samples from MBRs were collected every 10 days, and the degrading genes in MBR system were detected by q-PCR. As shown in figure 5, within 50 days after the introduction of bacteria, the number of copies of degrading genes in the immobilized bacteria system was constantly greater than that in the free bacteria system. In the first 10 days, DEHP degrading genes in CK system increased by $0.6 \times 10^{7}$ copies. $\mathrm{mg}^{-1}$, while T1 and T2 increased by $1.8 \times 10^{7}$ copies. $\mathrm{mg}^{-1}$ and $2.4 \times 10^{7}$ copies $\cdot \mathrm{mg}^{-1}$, respectively. This result proved that immobilization can shorten the start-up time of the reactor. Then, the number of DEHP degrading genes in the immobilized and non-immobilized systems continued to increase, while the growth rate of DEHP degrading genes in the immobilized system was faster than that in the non-immobilized system. On the fiftieth day, the difference of 3,4-Dioxygenase gene number between $\mathrm{T} 1$ and $\mathrm{T} 2$ systems was the greatest. The number of 3,4-Dioxygenase genes in T1 system was $6.8 \times 10^{7}$ copies $\mathrm{mg}^{-1}$, which was $3.1 \times 10^{7}$ copies $\cdot \mathrm{mg}^{-1}$ less than that in T2 system. These results indicated that immobilization technology can promote the increase of the number of the degrading gene, 3,4-dioxygenase. 


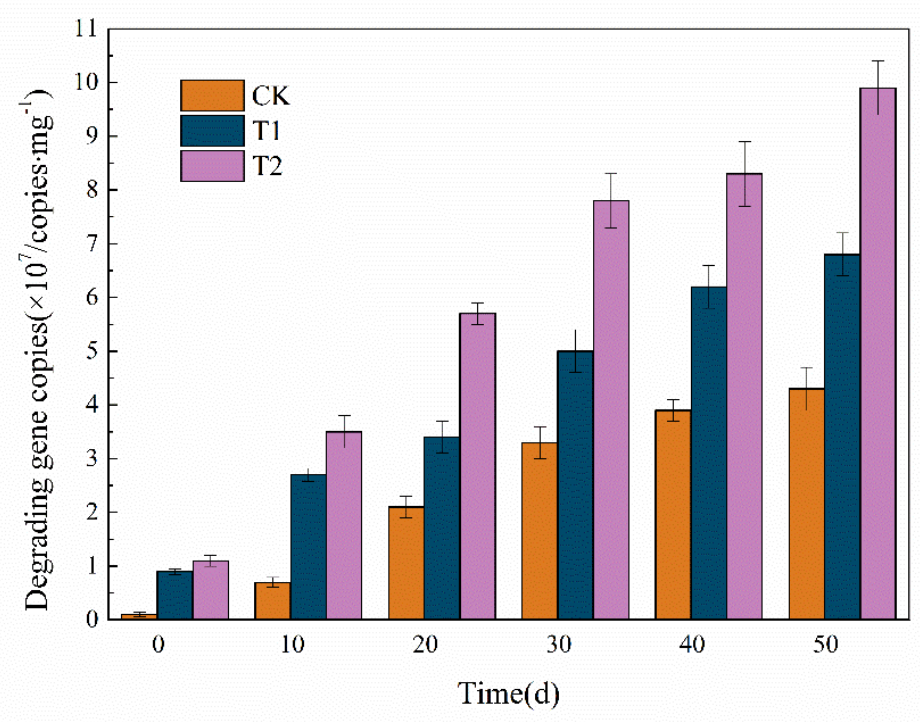

Figure 5. Number of bacterial 16S rDNA gene copies in sludge samples after introducing blank pellets (CK),free bacteria (T1) and immobilized bacteria (T2) by q-PCR extraction.

\subsection{Dynamic analysis of bacterial community structure}

Activated sludge samples were collected every 10 days and sequencing by Illumia miseq. Figure 6 shows the change of bacterial community composition at the phylum level with time in the system, and the inoculation of free bacteria and immobilized bacteria both changed the bacterial community structure. As shown in figure 6 (a), $\beta$-proteobacteria, Bateroidetes, Firmicutes and Deferribacteres were the main phylum in the primary activated sludge, accounting for about $55 \%$ of the total. With the process of domestication, the contents of Fibrobacteres, Actinobacteria and $\gamma$-Proteobacteria increased. Notably, the relative abundance of $\gamma$-Proteobacteria increased significantly after the inoculation of free bacteria, from $2 \%$ to $20 \%$ (figure 6 (b)). It was related to the addition of SAS-7. Similar to the system with free bacteria (T1), $\gamma$-Proteobacteria was also significantly increased in the system with immobilized bacteria (T2) were added. However, in the T2 system, $\gamma$-Proteobacteria increased more significantly, from $2 \%$ to $29 \%$ (figure 6 (c)). In a word, the trend of bacterial community change was similar in T1 and T2 system, but the change was more obvious in T2 systems, and Fibrobacteres, Actinomycetes and $\gamma$-Proteobacteria were the predominant phylum for DEHP biodegradation in the activated sludge. 
(a)

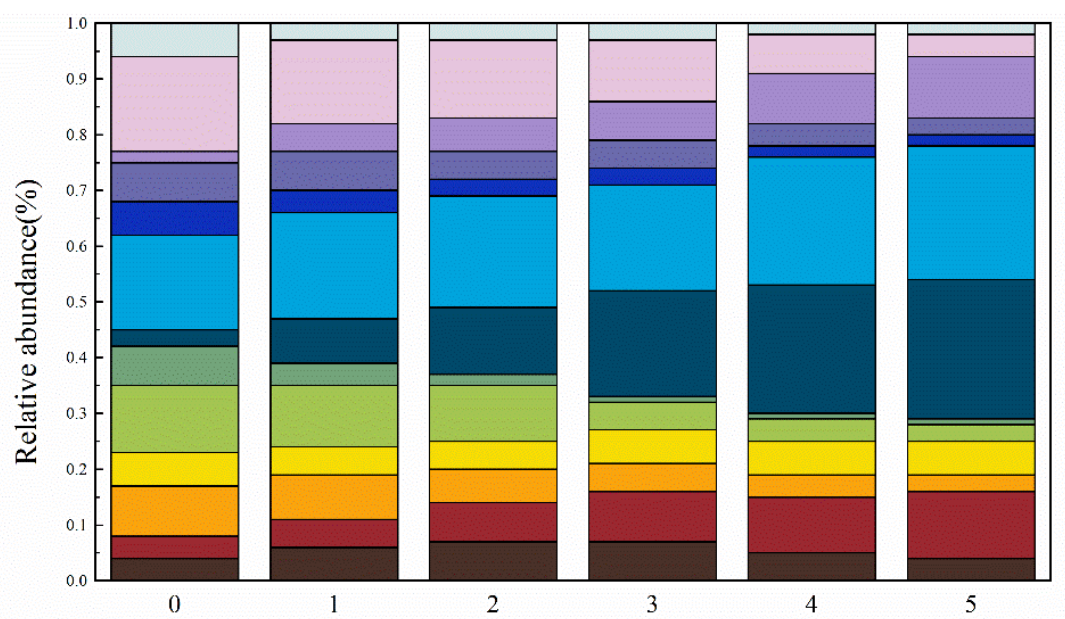

(b)

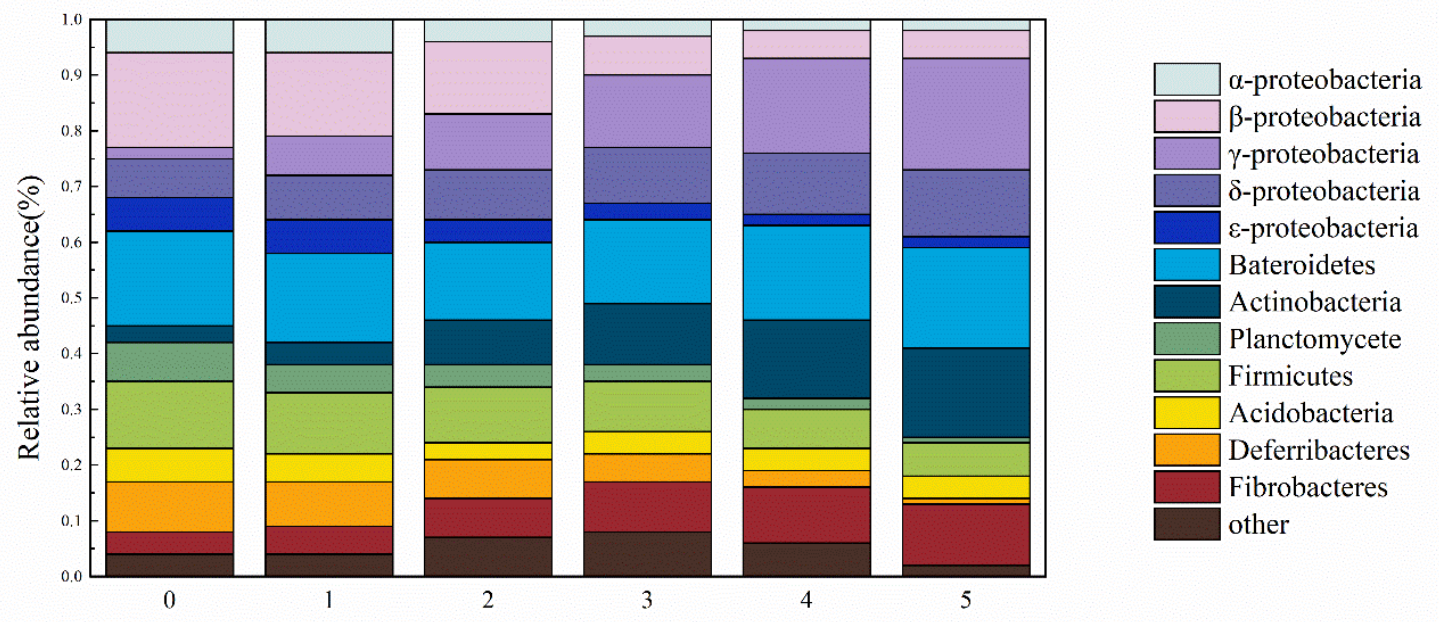

(c)

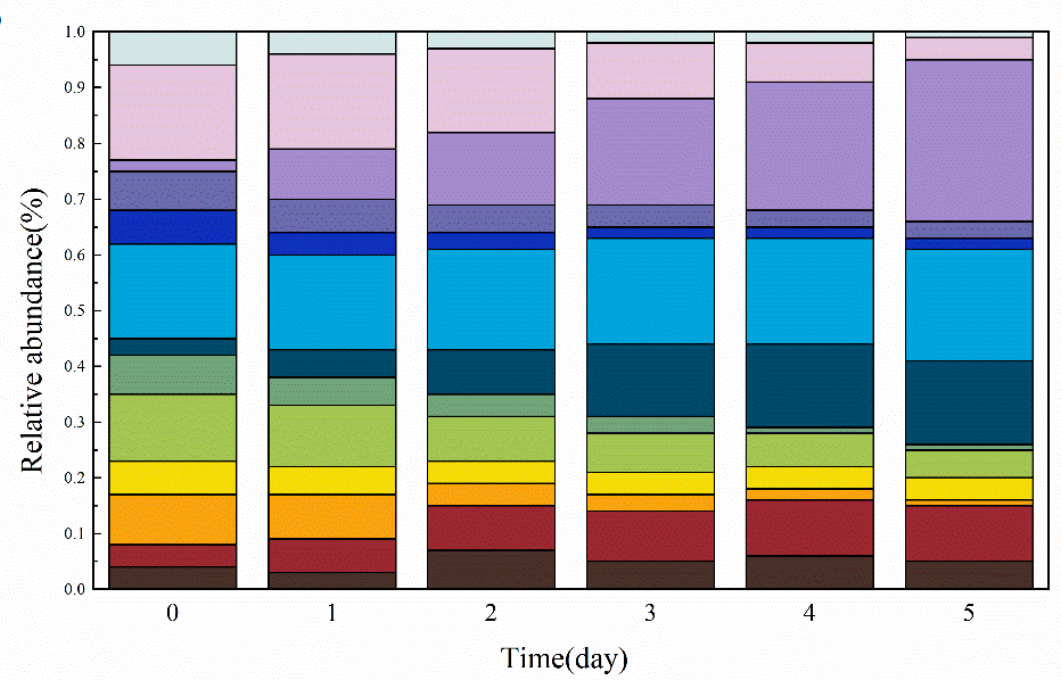

Figure 6. Bacterial community composition of activated sludge samples at phylum classification level (a) blank control CK; (b) free bacterial system T1; (c) immobilized bacterial system T2

The bacterial community dynamics in MBR system at the genus level is shown in figure 7. As shown in figure 7 (a), Nitrospira, Clostridium, Nitrosomonas, Comamonas and Micropruina were the main bacterial groups at the genus level in the primary activated sludge, accounting for about $69 \%$ of the total. As the domestication process deepened, all these dominant genera decreased significantly, with Nitrospira, Clostridium and Nitrosomonas dropped to $1 \%$ and $2 \%$ respectively, and Micropruina and Comamonas disappeared, suggesting these genera were less tolerant to DEHP toxicity. As shown in 
figure 7 (b), in the system inoculated with free bacteria, Pseudomonas increased significantly, and Nitrospira remained at a relatively stable constant during the whole trial. Similar to the T1 system, Pseudomonas also increased significantly in the T2 system which may be related to the addition of SAS-7 bacteria (figure 7 (c)). It was notablethat there were some genera disappeared in both CK and T1 system, while no genus disappeared in the T2 system. These results suggested that adopting immobilization technology had a positive effect on maintaining the microbial diversity of the MBR system.

(a)

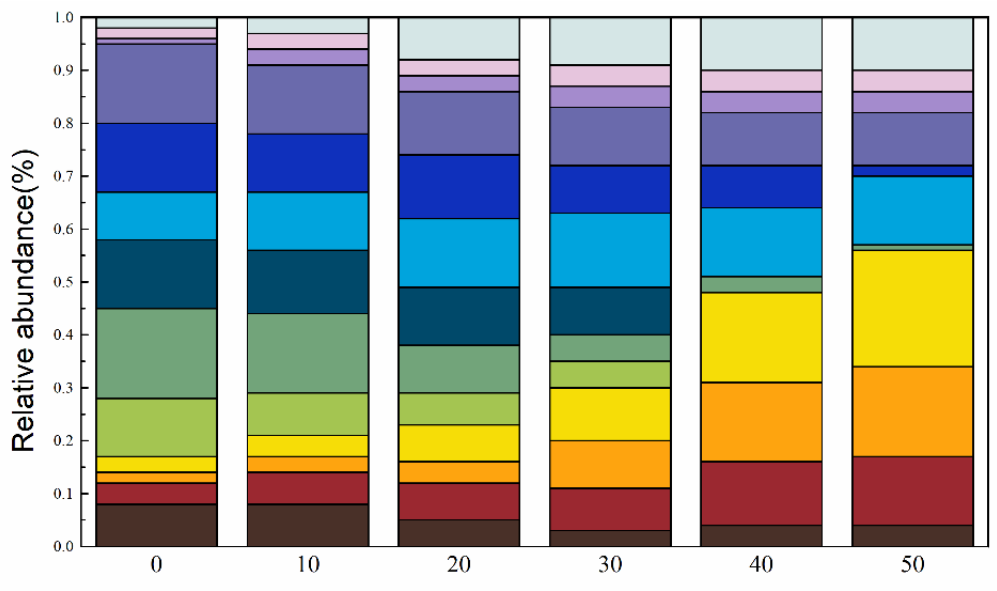

(b)

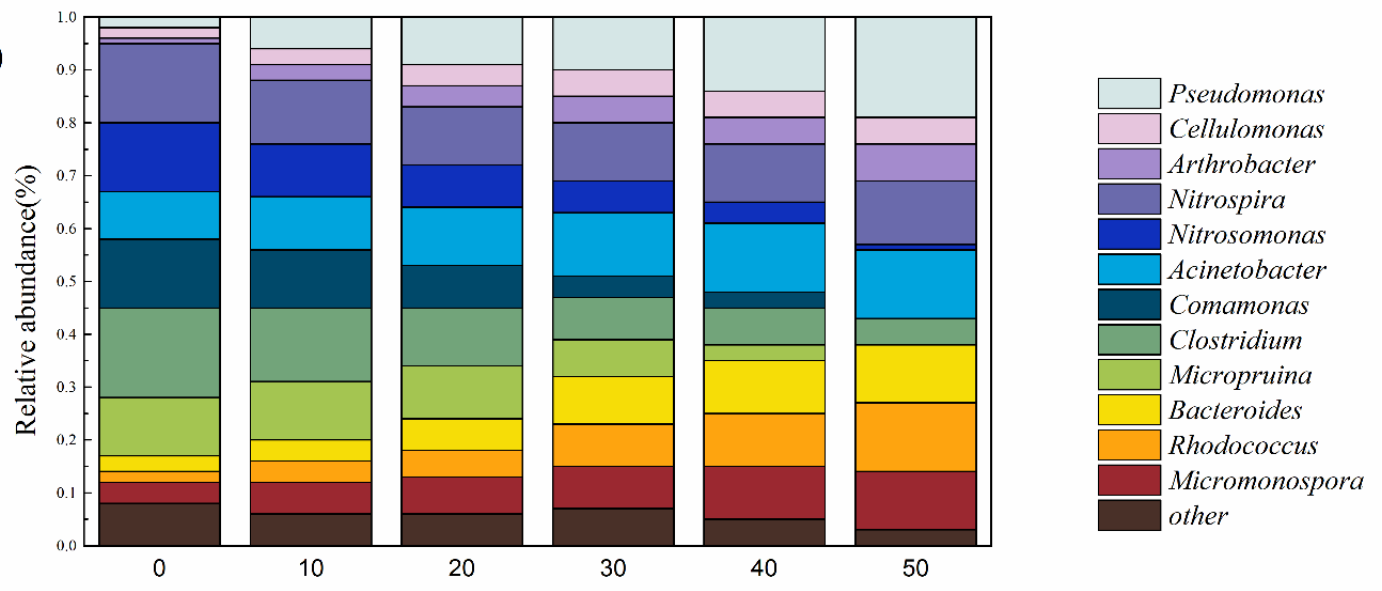

(c)

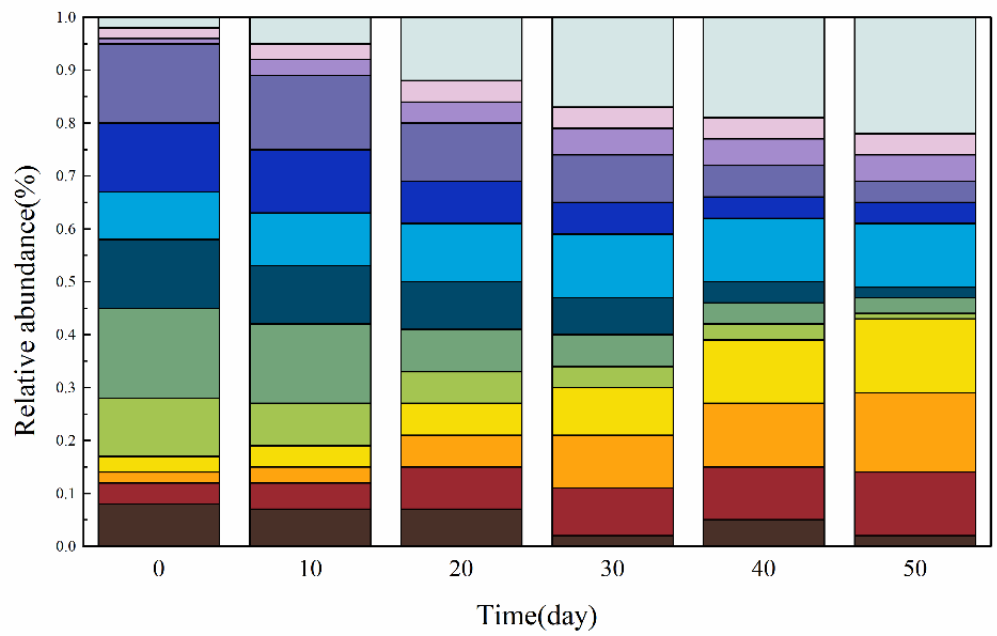

Figure 7. Bacterial community composition of activated sludge samples at genus classification level (a) blank control CK; (b) free bacterial system T1; (c) immobilized bacterial system T2 


\section{Discussion}

In this study, sodium alginate and calcium chloride were used as embedding and cross-linking materials to immobilize a DEHP degradable strain of Bacillus sp. SAS-7 isolated from activated sludge. Orthogonal experimental results showed that the effects of four factors on the immobilization were in the following order: the mass fraction of sodium alginate $>\mathrm{CaCl}_{2}$ mass fraction $>$ bacteria and sodium alginate volume ratio $>$ cross-linking time. Previous studies have shown that excessively low $\mathrm{CaCl}_{2}$ mass fraction may reduce the exchange rate between $\mathrm{Ca}^{2+}$ and $\mathrm{Na}^{+}$, thus reducing the degree of cross-linking between $\mathrm{Ca}^{2+}$ and sodium alginate, weakening the coagulation ability, and finally leading to low DEHP removal rate [37, 38]. The optimal crosslinking time was between $5 \mathrm{~h}$ and $7 \mathrm{~h}$, possibly because too short a crosslinking time may lead to cell instability and leakage, and too long a crosslinking time may lead to reduced bacterial activity [39]. However, whether a better immobilization condition exists remains to be studied.

To ensure microorganisms will not cause secondary pollution when degrading strains were applied to environment remediation. It is necessary to detecte the metabolites and intermediates of degradation bacteria before putting them into use. The metabolites detected in this paper were similar to those reported in the past (W, 2001; Stingley, 2004). DEHP was completely mineralized during the degradation process. Acinetobacter had been found to produce esterolytic enzymes [40], which are widely used for ester-bond hydrolysis and transesterification [41]. We speculate the degration pathway of DEHP by SAS-7 was as follows: the 3-4 bit carbon chain of DEHP was shortened and decomposed into DBP to further generate DEP, and then DEP was gradually transformed into PA through deesterification. The reasult is similar to Tang's (Tang et al. 2016). And according to previous papers, it had been proved to be a common and effective pathway in PAEs bioremediation; the grampositive bacteria oxidize and dehydrogenate at the C-3-4 position of phthalic acid to form 3, 4dihydroxy phthalic acid, protocatechins and finally enter TCA cycle [42, 43]. Different from Predee, we have detected PA in the degration progress [44]: PA used to be regarded as the key to complete the mineralization of DEHP, as it is easier to be utilized by microorganisms than DEHP [45]. What's more, our reasult is different from Xu et al's reports on Acinetobacter SN13: They didn't have detected DEP in the degradation process, but only did detected MEHP [44,46]. On the one hand, this could be because the reaction was too fast for detecting these intermediates, on the other hand, it may due to a better and unkown degration pathway exised. In short, there are still many problems on the degrading pathway of DEHP by Bacillus aerophilu remain unresolved. Therefore further study is worthwhile.

The DEHP degrading bacteria were immobilized under the optimum conditions. Then we introduced the immobilized degrading bacteria and the free degrading bacteria into the reactors. The removal rates of COD and DEHP were tested once a day. During the first ten days of the experiment, there was no significant change in the degradation rates, which may be because the microbes were in the adaptive phase. From the 12th day, the degradation rate of DEHP in each reactor increased rapidly, which indicated that bacteria began to multiply in large quantities. The degradation effect of immobilized bacteria was greater than that of free bacteria, which indicated that the immobilization technology could improve the degradation efficiency of DEHP. What's more, according to the change of COD and DEHP removal rates, we speculated the T2 system was stable on the 44th day, while the T1 system was stable on the 45th day: This indicates that adding the immobilized degrading bacteria could shorten the start-up time of the reactor. On the 47th day, the removal rates of DEHP and COD were significantly higher than those of $\mathrm{T} 1$ and $\mathrm{CK}$ systems. This indicates that the introduction of bioimmobilization technology could not only shorten the start-up time of the reactor, but also improve the degradation rate and effect of DEHP. This result is also confirmed in other studies [39, 47]. It may be because there were some strains or substances which were competitive or poisonous with DEHP degrading bacteria in the wastewater. And immobilized technique can be used to isolate and protect bacteria to a certain extent, creating a better living environment for degrading bacteria. In shorts, adopting the immobilized technique improved the DEHP removal efficiency of the MBR system: It is confirmed to be available to MBR system, which deserves futher study. 
The 3,4-Dioxygenase gene in the reactor was analyzed by q-PCR. It was found that the number of DEHP degrading genes in $\mathrm{T} 1$ system was significantly less than that in $\mathrm{T} 2$ system. Combining with the analysis of figure 6 and figure 7, the ratio of DEHP degrading genes and the removal rate of DEHP was proportional, which indicated that the high copy number of DEHP degrading genes was the guarantee of the removal rate of DEHP. The number of 3,4-Dioxygenase gene copies in immobilized bacteria system was $1 / 3$ higher than that in free bacteria system, which indicated that the use of immobilization technology could promote the growth of DEHP degradation gene copies. The quantitative relationship of DEHP Degrading genes in free bacteria and immobilized bacteria systems can also explain the difference of DEHP degrading rate (figure 5).

In the MBR system, microorganism is the key to remove organic pollutants. The reason for the higher efficiency of immobilized reactor treatment is that the relative abundance of Bacteroides sp. (SAS-7) added to the system has been maintained at a high level. This result indicates that immobilization technology can effectively protect target bacteria from invasion of competitors and natural competition of native microorganisms. In addition, as the degrading bacteria was introducted, the bacterial population structure in the system changed; It caused a change in the degration effect. After introduced the immobilizd degrading bacteria to T2 system, Micromonospora, Rhodococcus, Bacteroides and Pseudomonas, which have been reported to be able to remove DEHP, increased and finally became the dominant geuns in the system $[48,49]$. This indicates that the change of microbial community caused by immobilized bacteria is more conducive to DEHP degradation. What's more, there was no bacteria in T2 system that disappeared, during the domestication process, while Comamonas and Micropruina were gradually disappeared in CK and T1 systems. This reasult shows that the addition of immobilized bacteria may have a certain equilibrium effect on the bacterial community structure in the reactor. Generally speaking, adopting immobilization technology can not only protect degrading bacteria, but also regulate and balance the bacterial structure in the system.

\section{Conclusions}

A strain capable of highly degrading DEHP was isolated from activated sludge, and identified as bacillus $s p$.. The degradation pathways were deduced as follows: from phthalic acid (2-ethylhexyl) ester (DEHP) to dibutyl phthalate (DBP) and diethyl phthalate (DEP), then further enzymatic hydrolysis to phthalic acid (PA), and finally completed mineralization. Orthogonal experiment indicates that the optimal immobilization condition is SA mass fraction of $4 \%, \mathrm{CaCl}_{2}$ mass fraction of $5 \%$, ratio of bacteria to SA of 1:1, and crosslinking time of 6 hours. The immobilization technique significantly improved the biodegradation efficiency of DEHP in MBR. The removal rate of DEHP in the immobilized system was $91.1 \%$, and the copy number of degraded genes was $1 / 3$ higher than that in the free bacteria system. The 3, 4-dioxygenase gene was positively correlated to the DEHP degradation. Immobilized technique effectively protected the DEHP degrading bacteria in MBR, and Micromonospora, Rhodococcus, Bacteroides and Pseudomonas were the dominant genera. Results from this study suggest that immobilization technique has potential application for DEHP removal.

Acknowledgments: This work was supported by the National Natural Science Foundation of China (No. 51808363), and the Development Project of Science and Technology benefitting the Public in the Science \& Technology Bureau of Chuengdu City (No. 2015-HM01-00325-SF).

Conflicts of Interest: The authors declare no conflict of interest.

\section{Figure captions}

Fig.1 MBR flow chart and reactor (1. Water creeping pump; 2. Membrane module; 3. Flow meter; 4. Aeration device; 5 . Pressure gauge; 6 . Outlet peristaltic pump; 7.Water bath circulating device)

Fig.2 Phylogenetic tree of SAS-7 and its related species based on 16S rRNA gene sequence (The gene library number of each bacterial isolate is written in parentheses, and the number on each branch node is based on the guiding value of 1000 resampling.) 
Fig.3 Proposed pathways of DEHP degradation by strain SAS-7 (substrates marked by dotted lines is undetected in GC-MS)

Fig.4 Removal effect of free bacteria (T1) and immobilized bacteria (T2) in MBR reactor on DEHP

Fig.5 Number of degrading gene (3,4-dioxygenase) copies in sludge samples after introducing blank pellets (CK),free bacteria (T1) and immobilized bacteria (T2) by q-PCR extraction .

Fig. 6 Bacterial community composition of activated sludge samples at phylum classification level (a) blank control CK; (b) free bacterial system T1; (c) immobilized bacterial system T2

Fig. 7 Bacterial community composition of activated sludge samples at genus classification level (a) blank control CK; (b) free bacterial system T1; (c) immobilized bacterial system T2

\section{Table list}

Table 1. Factors and levels of orthogonal experiment design

Table 2. Orthogonal experimental results of immobilized DEHP degrading bacteria.

\section{References}

[1]. Bergman, A., et al., State of the science of endocrine disrupting chemicals 2012: an assessment of the state of the science of endocrine disruptors prepared by a group of experts for the United Nations Environment Programme and World Health Organization. 2013.

[2]. Lyche, J.L., et al., Reproductive and developmental toxicity of phthalates. Journal of Toxicology \& Environmental Health Part B, 2009. 12(4): p. 225-249.

[3]. Yin, R., et al., Effect of DBP/DEHP in vegetable planted soil on the quality of capsicum fruit. Chemosphere, 2003. 50(6): p. 801-805.

[4]. Liu, Y., Z. Chen and J. Shen, Occurrence and Removal Characteristics of Phthalate Esters from Typical Water Sources in Northeast China. Journal of Analytical Methods in Chemistry,2013,(2013-03-12), 2013. 2013(2): p. 419349.

[5]. Per Axel, C., et al., Influence of temperature on the emission of di-(2-ethylhexyl)phthalate (DEHP) from PVC flooring in the emission cell FLEC. Environmental Science \& Technology, 2007. 41(15): p. 3217-3224.

[6]. Xia, X., et al., Levels, distribution, and health risk of phthalate esters in urban soils of Beijing, China. Journal of Environmental Quality, 2011. 40(5): p. 1643.

[7]. Ma, T., et al., Removal of phthalic esters from contaminated soil using different cropping systems: A field study. European Journal of Soil Biology, 2012. 50(3): p. 76-82.

[8]. Huang, D.Y., et al., Pollution characteristics of volatile organic compounds, polycyclic aromatic hydrocarbons and phthalate esters emitted from plastic wastes recycling granulation plants in Xingtan Town, South China. Atmospheric Environment, 2013. 71(3): p. 327-334.

[9]. Yao, H., et al., Determination and analysis of the five phthalates in environmental water samples in Anshan city. Sciencepaper Online, 2011.

[10]. Xu, G., F. Li and Q. Wang, Occurrence and degradation characteristics of dibutyl phthalate (DBP) and di(2-ethylhexyl) phthalate (DEHP) in typical agricultural soils of China. Science of the Total Environment, 2008. 393(2): p. 333-340.

[11]. Xi, K.W., et al., Analysis of Phthalate Esters in Air, Soil and Plants in Plastic Film Greenhouse. Chinese chemical letters, 2002. 13(6): p. 557-560.

[12]. Gao, M., et al., Photosynthetic and antioxidant response of wheat to di(2-ethylhexyl) phthalate (DEHP) contamination in the soil. Chemosphere, 2018. 209: p. 258-267. 
[13]. Zhang, Y., et al., Effect of di- n -butyl phthalate on root physiology and rhizosphere microbial community of cucumber seedlings. Journal of Hazardous Materials, 2015. 289: p. 9-17.

[14]. Kong, S., et al., Diversities of phthalate esters in suburban agricultural soils and wasteland soil appeared with urbanization in China. Environmental Pollution, 2012. 170(8): p. 161-168.

[15]. Wu, M., et al., Involvement of oxidative stress in di-2-ethylhexyl phthalate (DEHP)-induced apoptosis of mouse NE-4C neural stem cells. NeuroToxicology, 2019. 70: p. 41-47.

[16]. Zhang, Y., et al., Di (2-ethylhexyl) phthalate (DEHP)-induced hepatotoxicity in quails (Coturnix japonica) via triggering nuclear xenobiotic receptors and modulating cytochrome P450 systems. Food and Chemical Toxicology, 2018. 120: p. 287-293.

[17]. Muchangos, L.D., et al., Flows, stocks, and emissions of DEHP products in Japan. Science of The Total Environment, 2019. 650: p. 1007-1018.

[18]. Yan, L., et al., Assessing the Risk of Phthalate Ester (PAE) Contamination in Soils and Crops Irrigated with Treated Sewage Effluent. Water, 2018. 10(8).

[19]. Ahuactzin-Pã Rez, M., et al., Degradation of di(2-ethyl hexyl) phthalate by Fusarium culmorum: Kinetics, enzymatic activities and biodegradation pathway based on quantum chemical modelingpathway based on quantum chemical modeling. Science of the Total Environment, 2016. 566-567: p. 1186-1193.

[20]. Staples, C.A., et al., The environmental fate of phthalate esters: A literature review. Chemosphere, 1997. 35(4): p. 667-749.

[21]. Gledhill, W.E., et al., An environmental safety assessment of butyl benzyl phthalate. Environmental Science \& Technology, 1980. 14(3): p. 301.

[22]. Zhao, H., et al., Biodegradation pathway of di-(2-ethylhexyl) phthalate by a novel Rhodococcus pyridinivorans $\mathrm{XB}$ and its bioaugmentation for remediation of DEHP contaminated soil. Science of The Total Environment, 2018. 640-641: p. 1121-1131.

[23]. Iwaki, H. and Y. Hasegawa, Isolation and characterization of marine bacteria capable of utilizing phthalate. World Journal of Microbiology \& Biotechnology, 2012. 28(3): p. 1321-1325.

[24]. Nahurira, R., et al., Degradation of Di(2-Ethylhexyl) Phthalate by a Novel Gordonia alkanivorans Strain YC-RL2. Current Microbiology, 2017. 74(3): p. 1-11.

[25]. Zhao, H.M., et al., Complete degradation of the endocrine disruptor di-(2-ethylhexyl) phthalate by a novel Agromyces sp. MT-O strain and its application to bioremediation of contaminated soil. Science of the Total Environment, 2016. 562: p. 170-178.

[26]. Benjamin, S., et al., A monograph on the remediation of hazardous phthalates. Journal of Hazardous Materials, 2015. 298: p. 58-72.

[27]. Tang, W.J.Z.L., Biodegradation of phthalate esters by newly isolated Rhizobium sp. LMB-1 and its biochemical pathway of di-n-butyl phthalate. Journal of Applied Microbiology, 2016. 1(121): p. 10.

[28]. Cho, Y.H. and D. Knorr, Development of a gel and foam matrix as immobilization system for cells for microbial denitrification of water. Food Biotechnology, 1993. 7(2): p. 115-126.

[29]. Dong, H., et al., A high-efficiency denitrification bioreactor for the treatment of acrylonitrile wastewater using waterborne polyurethane immobilized activated sludge. Bioresource Technology, 2017. 239: p. 472-481.

[30]. Ke, Z., et al., Bacterial community dynamics and enhanced degradation of di- n -octyl phthalate (DOP) by corncob-sodium alginate immobilized bacteria. Geoderma, 2017. 305: p. 264-274.

[31]. Jiang, Y., et al., Immobilization of halophilic yeast for effective removal of phenol in hypersaline conditions. Water Science and Technology, 2018. 3(77): p. 706-713.

[32]. Fang, C.R., et al., Dibutyl phthalate degradation by Enterobacter sp. T5 isolated from municipal solid waste 
in landfill bioreactor. International Biodeterioration \& Biodegradation, 2010. 64(6): p. 442-446.

[33]. Tahhan R A, A.T.G.G., Enhancing the biodegradation of total petroleum hydrocarbons in oily sludge by a modified bioaugmentation strategy. International Biodeterioration \& Biodegradation, 2011. 1(65): p. 130-134.

[34]. Jing, Z., et al., Influence of 34-years of fertilization on bacterial communities in an intensively cultivated black soil in northeast China. Soil Biology \& Biochemistry, 2015. 90: p. 42-51.

[35]. Gao, C.X.Z.J., Structure characteristics of activated sludge microbial communities in nitrogen and phosphorous removal system of municipal wastewater. Chin. Water Wastewater, 2015. 23(31): p. 37-42.

[36]. Fadrosh, D.W., et al., An improved dual-indexing approach for multiplexed 16S rRNA gene sequencing on the Illumina MiSeq platform. Microbiome, 2014. 2(1): p. 6-6.

[37]. Hedayati, S., et al., Effects of $\mathrm{NaCl}$ and $\mathrm{CaCl} 2$ on physicochemical properties of pregelatinized and granular cold-water swelling corn starches. Food Chemistry, 2016. 213: p. 602-608.

[38]. Demirkan, E.D.E., et al., Immobilization of B. amyloliquefaciens alpha-amylase and comparison of some of its enzymatic properties with the free form. ROMANIAN BIOTECHNOLOGICAL LETTERS, 2011. 6(16): p. 66906701.

[39]. Zhang, K., et al., Bacterial community dynamics and enhanced degradation of di- $\mathrm{n}$-octyl phthalate (DOP) by corncob-sodium alginate immobilized bacteria. Geoderma, 2017. 305: p. 264-274.

[40]. Shabtai Y, G.D.L., Exocellular esterase and emulsan release from the cell surface of Acinetobacter calcoaceticus. Journal of Bacteriology, 1985. 3(161): p. 1176-1181.

[41]. Rao L, X.Y.Z.Y., A novel alkaliphilic bacillus esterase belongs to the 13(th) bacterial lipolytic enzyme family. Plos One, 2013. 4(8): p. e60645.

[42]. Stingley, R.L.B.B., Novelorganizationofgenesin a phthalate degradation operon of Mycobacterium vanbaalenii PYR-1. Microbiology, 2004(150): p. 3749-3761.

[43]. Xu, J., et al., Degradation of di-2-ethylhexyl phthalate (DEHP) by an indigenous isolate Acinetobacter sp. SN13. International Biodeterioration \& Biodegradation, 2017. 117: p. 205-214.

[44]. Pradeep S, J.M.K.S., Achromobacter denitrificans strain SP1 efficiently remediates di(2ethylhexyl)phthalate. Ecotoxicology \& Environmental Safety, 2015(112): p. 114-121.

[45]. Roslev P, M.P.L.T., Degradation of phthalate and Di-(2-Ethylhexyl)phthalate by indigenous and inoculated microorganisms in sludge-amended soil. Appl Environ Microbiol, 1998. 12(64): p. 4711-4719.

[46]. Jiaming $\mathrm{Xu}$, Q.L.R.A., Degradation of di-2-ethylhexyl phthalate (DEHP) by an indigenous isolate Acinetobacter sp. SN13. International Biodeterioration \& Biodegradation, 2017(117): p. 205-214.

[47]. Alessandrello, M.J., et al., PAH removal by immobilized bacterial cells-support systems using low-cost culture media for biomass production. International Biodeterioration \& Biodegradation, 2017. 120: p. 6-14.

[48]. Xue, Y., et al., Isolation and characterization of two n -butyl benzyl phthalate degrading bacteria. International Biodeterioration \& Biodegradation, 2013. 76(1): p. 8-11.

[49]. Wen, Z.D., D.W. Gao and W.M. Wu, Biodegradation and kinetic analysis of phthalates by an Arthrobacter strain isolated from constructed wetland soil. Appl Microbiol Biotechnol, 2014. 98(10): p. 4683-4690. 